NOTICE: This is the author's version of a work that was accepted for publication in Automation in Construction. Changes resulting from the publishing process, such as peer review, editing, corrections, structural formatting, and other quality control mechanisms may not be reflected in this document. Changes may have been made to this work since it was submitted for publication. A definitive version was subsequently published in Automation in Construction, Vol. 31, (2013). doi: 10.1016/j.autcon.2012.10.007 


\title{
Incorporation of database approach into contractual issues: Methodology and practical guide for organizations
}

\begin{abstract}
A total avoidance of project disputes is an impossible situation. Yet, the purpose should be to identify the perspectives of minimizing disputes or maximizing avoidance. By referring to past experiences on the causes and the suggested solutions, this research reckons that it can assist in avoiding or resolving similar situations at the onset of the dispute occurrence. Therefore, the objectives of the present study are: (a) to propose and develop a practical database system that can be employed by organizations to manage the past experiences, particularly for contractual issues, and (b) to validate and evaluate the database system from related organizations. The development of the database was systematically articulated. Two actual projects were referred prior to finalizing the database system's structure. Microsoft Office Access tool was selected due to its widespread availability and user-friendliness to construction related organizations. The database system was evaluated by thirty professional quantity surveyors and received positive feedback. It renders an insight toward the effort in avoidance of project disputes through the database approach, which can be easily adopted by the organizations.
\end{abstract}

Keywords: Contractual issues; avoidance; methodology; database; construction 


\section{Introduction}

Projects would become more complex when involving a variety of different participant groups with different goals and needs $[1,2]$. Due to the different perceptions and conflicting goals among the project participants, disagreements are inevitable [3, 4]. Such disagreements could result in project disruption and a detrimental relationship between the contractual parties [5]. Consequently, the projects would be affected by time and cost overrun [4].

There are advantages in avoiding disputes when compared to the notion of assuming that disputes are inevitable, and resolving them after growing [6]. However, a total avoidance of the disputes in a project is a rather impossible situation. Hence, the research direction should be to identify the perspectives of minimizing disputes or maximizing avoidance. There is no method of resolving disputes without identifying the causes. The best method of resolving a dispute includes: (a) to detect the basic causes, and (b) remove these causes in advance [6].

This research focuses on construction projects as its complexity and dispute-prone in nature, particularly for contractual issues. By identifying the possible causes from past experiences, the construction players may seek to avoid or forestall similar situations in the future [7]. The experiences refer to the knowledge and skill that individuals have gained through doing something for a period of time [8]. It can be recorded in different forms and media of information and communication technologies for project management $[9,10]$ such as in the minds of the experts, in operating procedures or documents, databases and intranets $[11,12]$. The value of such experiences is immeasurable. Lessons learned from the past dispute cases could provide the project's stakeholders ideas on how to manage and resolve the current problem or subsequent cases [13]. Subsequently, it would assist in making good decisions and also preventing the problem from escalating toward the worst scenario.

As a result, the present study intends to present a database system that could be employed to share and transfer experiences of past disputes as well as provide useful information for 
dispute prevention or minimization. The database system performs both functions of a relational database and a data warehouse. The contents of the system were added by referring to two actual projects. The system was fully prototyped, however, it requires further development in terms of its contents to serve as the data warehousing through the continuous inputs from the organization.

Eventually, the system operates as a hub for coordination and communication support for knowledge sharing, which is able to improve the project performance [14]. The project performance can be improved through identification of the organization's strengths and weaknesses in handling and administering the contractual matters. Moreover, it also assists in dispute resolution and avoidance, for instance, if the disputants have access to a means that could obtain a better knowledge of possible outcomes resulting from the issue, it may facilitate resolving the issue voluntarily at an early stage [13].

\section{Conflicts and Disputes}

'Conflict' and 'dispute' are two distinct ideas [7]. However, most people probably do not recognize the differences between them. According to Cambridge Advanced Leaner's Dictionary $\left(3^{\text {rd }}\right.$ edition), conflict defines as a serious incompatibility between people with opposing opinions, ideas, principles or interest. On the other hand, dispute is defined as an argument or disagreement, especially an official one between, for example, workers and employers or two countries with a common border. Although in ordinary parlance the word of 'conflict' and 'dispute' are used interchangeably, but in fact, conflict is the precursor to a dispute.

Contractual types of conflicts or disputes are one of the root causes for project disputes, which are related the legal principles and contractual obligations in the contract documents [15]. Hence, this research focuses on contractual issues for the database development. In 
order to make clear the contractual issues involved in different stages, in this study, the contractual activities have been organized and arranged according to three main work stages. They are 'Pre-contract Award Stage', 'Construction or Commencement of Work Stage', and 'Post-Commencement Stage', which are modified from The Royal Institute of British Architects (RIBA) Plan of Works. The Plan of Works is shown in Table 1. Subsequently, the three work stages are:

- Pre-contract Award Stage: it relates to the activities involved covering project inception, feasibility, designing and tendering period.

- Construction or Commencement of Work Stage: it relates to the activities involved from the period of contract date starts and ends in a construction project. It would go until practical completion of the project as referring to RIBA Plans of Work. For the ease of classification, the practical completed work would complete before or same on the completion date according to the contract period.

- Post-Commencement Stage: it relates to the activities involved for the period after the practical completion or post practical completion as referring to RIBA Plans of Work.

\section{Information System: Database Approaches toward Project Disputes}

Traditionally, techniques utilized by the construction professionals to transfer experiences often required face-to-face actions, e.g. formal meetings, interviews, etc [12]. However, by employing a database system, a huge amount of data can be handled, properly managed, and referred to easily and quickly [16]. The database collects the experiences from the minds of different people and acts like a central storage to provide references and guidelines to a user's query in a particular manner [17]. 
Despite the increased development of databases in the construction industry [18], a database that deals with contractual disputes is a relatively new concept in the information system. Several previous studies of database applications were reviewed between 2002 and 2011 as shown in Table 2. In general, it can be concluded that a majority of the database applications are related to information management and cost estimation. In addition, the data warehouse and the relational database are the two main types of database applications that involved in the areas of research. The data warehouse is a read-only analytical database that provides a tool-helping project organization in decision making [19]. It plays an important role in a decision support system. On the other hand, the relational database is a database that recognizes the relationships between the different pieces of information [8]. It stores and manages the required information in the database system. Nonetheless, the proposed database system is not exactly a data warehouse or relational database, but is more toward a combination of them. It is not a read-only analytical database or data storage, but it supports the function to enhance knowledge of users in decision making.

An addition to that, several studies have also suggested approaches for overcoming the problem of disputes in the construction industry as shown in Table 3. Shin and Molenaar [13] presented a framework for dispute prediction by defining the critical dispute characteristics and building causal relationships amongst these characteristics. Cheung and others [5] proposed a method to evaluate the construction dispute by applying the fuzzy set theory to analyze the likelihood of occurrence and impact of a dispute. Kassab and others [26] used the graph model to predict decisions during the negotiation process. It provided valuable insights into the strategic characteristics of a dispute. Chen and Hsu [27] developed a model to resolve a potential severe dispute caused by the change orders developed. The model utilized the artificial neutral networks (ANN) to predict the litigation likelihood and case based reasoning $(\mathrm{CBR})$ to yield warnings and display the litigation information related to past 
cases. Chen [4] also developed a knowledge sharing model for information sharing, which was aimed to avoid a litigious construction change dispute. Last but not least, Cheng and others [1] combined the CBR and fuzzy set theory for coping with the construction disputes. It would assist mediators to make decisions in dispute settlement and provide information to the project participants for defending their rights.

Consequently, it can be observed that each study utilizes a different technique in dealing with construction disputes. However, a majority of the techniques involve the complicate theory, which is not easy to comprehend and lack of practical examples for a real practice. In addition, it can be established that historical data or cases were involved in a majority of the studies. Thus, the usefulness and effectiveness of past knowledge or experiences in dealing with the construction dispute have been recognized. The above overview is useful to clarify the differences between the present study and the other previous approaches in terms of the concept and function of database application as well as the method in dealing with the construction disputes.

\subsection{Database's features and development}

A database is a shared, integrated computer structure that stores information about the types, attributes and relationship of the entities [28]. The term database system refers to an organization of components that refine and regulate the collection, storage, management and use of data within a database environment [29]. In the present study, the database system consists of four major components as illustrated in Fig. 1 such as:

- Hardware refers to the system's physical devices, for example, computer, monitor, etc.

- Software refers to the database management system software. Recently, many types of database tools are available in the market such as Oracle, International Business 
Machines Data Base 2 (IBM DB2), Microsoft Office Access, System Query Language (SQL) Server, Sybase, etc. In the present study, Microsoft Office Access was chosen due to its widespread availability, lower cost [24], and ease of learning. Further, the software is readily available and provides a simple and user-friendly interface.

- People include all the users of the database system. Four types of users have been identified: database system administrator who oversees the database system's operation and ensures the proper functioning, data administrator who manages the data and supports the validity of the information, users who are with the relevant experiences and knowledge in storing the data, and users who are looking for relevant references in extracting the data.

- Data covers the collection of facts stored in the database. In the present study, the word data refers to the experiences of the past contractual dispute in a construction project.

A database can be classified according to the number of users as well as the database location [29]. The numbers of users determine whether the database can support only one user at a time (single-user database) or multiple users at the same time (multi-user database). Meanwhile, the database location determines whether the database can support the data located at a single site (centralized database) or distributed across several different sites (distributed database). In the present study, the proposed database is a centralized database, which is utilized to manage the contractual disputes within a company or an organization. It also serves a single-user database that allows only one user to access at a time. Although, two or more users are able to access the database at the same time, the second and following users can just open the read-only database. This is to prevent the users from making conflicting 
changes to the same data at the same time [30]. However, it can be transformed into a multiuser database or distributed database by applying the web-application platform, for example, Active Server Pages (ASP.NET), Microsoft Share Point, etc. This requires an internet connection as well as better control system and management.

Besides, a good database refers to a database that meets all the user requirements and could improve company's portfolio management, which is a group of projects that share the common resources $[29,31]$. The database system contains database objects such as tables, queries, forms, reports, macros and modules [16]. The functions of the objects include: tables for storing the data, queries for selecting and combining data, forms for viewing or editing

the data on-screen, reports for printing the data, macros and modules for programming automation $[32,33]$. The development of the database has been carried out manually. Few contract documents and database examples have been referred to determine the type of information and structure that should be provided by the database.

\subsection{Conceptual Model}

Two case studies were conducted prior to the development of database system to form a template example of data entry. This process would provide chances to verify the functionality of the database's structure in terms of its features, interfaces, and the information that reviewed from literatures. The contract documents were referred to gather the information related to the contractual issues that encountered in the project. Interviews were also carried out with the contract managers who handled the projects. The interviews made clear the data used from the contract documents as well as to check the completeness of the database' structure.

Subsequently, a conceptual model was developed. It is an abstraction of some aspects of the real-world [29]. A model enables a clearer communication about the aspects of the real- 
world and serves as a blueprint to shape and construct the proposed structures [34]. In the present study, the database system aims to manage the contractual issues and provide references to users in the construction industry. Three requirements must be fulfilled for this purpose. Firstly, the database must be simple and easy for the users to insert the data. Secondly, the specific data stored in the database must be found easily and quickly. Lastly, the users must be allowed to manage or edit the existing data.

As a result, the conceptual model describes the requirements of the database system in a process flow as illustrated in Fig. 2. The database is the main component of the system that stores all the relevant data. Data entry provides a means for the users to store the experiences and knowledge into the database. The users must ensure that the particulars of the project have been set up before inserting the details of the issue. The search component provides a tool for the users to extract references from the database. The users may either search on a specific issue for different projects or on all issues for a selected project based on the project characteristics. This conceptual model serves as the main framework for the subsequent development of the database system.

Furthermore, a total of thirty nine contractual issues were identified and derived from literature review through three work stages as shown in Table 4. The users may select the relevant issue from the list during the process of inserting or searching the data. However, it does not mean that the contractual issues are only limited to the above-mentioned thirty nine areas. The users are allowed to add in any new issues into the list after obtaining approval from the data administrator. In addition, the project characteristics utilized to retrieve and sort out a list of the search results are referred to the four elements: construction type (building construction, infrastructure construction, etc.), contract type (fixed firm price contract, lump sum contract, etc.), procurement method (traditional, design \& build, etc.), and standard form of contract (International Federation of Consulting Engineers (FIDIC), Joint Contracts 
Tribunal (JCT), etc.). By selecting any or all of the elements, the historical data with similar characteristics will be sorted out, as requested by the users.

Two types of information are required in the process of setting up a new dispute issue, such as the description of the issue, and the action or solution of dealing with the issue. The description would depict the occurrence of the dispute like the causes, parties involved, and any matters that affect the transformation of the issue. The action or solution describes the manner of dealing with or resolving the dispute event by the parties. It includes the selection of dispute resolution method, process, and outcome.

\section{Contractual Database System}

Contractual Database System (CDS) was developed using Microsoft Office Access based on the model presented in the previous section. The key components include tables, forms, and macros. The database of CDS consists of two tables. The first table captures the project particulars as shown in Table 5. It consists of eighteen fields. This is important as the different project characteristics will have different effects on the contractual issue. The project characteristic will help the users to refine their search. On the other hand, the second table captures the details of the contractual issues. It consists of seven fields as shown in Table 6.

A parent-child or one-to-many relationship has been set between the tables as illustrated in Fig. 3. The table of project particulars is the parent table; whereas the table of contractual issues is the child table. It has been demonstrated that a single project can have any number of contractual issues, but each issue may only refer to a single project. Subsequently, several forms have been created from the tables, while the macros have been set up to automate the custom tasks. The forms are the database objects with attractive interfaces to provide an easy way of viewing or changing the information in a table. Each form of CDS will be discussed 
in detail in the following section. Fig. 4 illustrates the overall framework of the database system.

\subsection{Main menu / 'Home'}

The first interface of CDS describes as the main menu or 'Home'. It is the front page of the system. This is the location where the missions commence and end. Four selections are available in the main menu such as search, data entry, database, and quit. Each selection opens up a sub-menu for further information. For instance, the 'search' option provides a tool for the users to extract data from the system. The 'data entry' option provides a means for users to insert and save the data. The 'database' option is the warehouse for storing the data as well as a place for the users to manage the data. The 'quit' option is used to close the system. The main menu of CDS is illustrated at beginning section of Fig. 4.

\subsection{Search}

The search interface will be displayed after selecting the 'search' button in the main menu. Two options are available in this sub-menu such as project and issue. Both options provide an individual search tool for users to locate the references. The 'project' search tool locates the different contractual issues, which could be retrieved from a particular project. The users may extract the related references from the system based on the project characteristic like construction type, contract type, procurement method, or standard form of contract. The relevant projects will be sorted out in a list after meeting the criteria of the query. From the

list, the users are free to open any projects and review the contractual issues that developed in the project.

Meanwhile, the 'contractual issue' search tool extracts a specific contractual issue, which could have occurred in different projects. It is quite similar with the 'project' search tool. 
However, the search tool extracts the references based on a specific contractual issue that sorted out from the thirty six contractual issues.

\subsection{Data entry}

By selecting the data entry feature, a sub-menu will be displayed. Two options are available such as new project and new issue. If a project has never been recorded in the system, the users are recommended to select the 'New Project' button. After that, the users require to fill up the project particulars such as name, title, location, project characteristics, name of the project team member, contract value, and project duration.

After the project particulars have been recorded in the system, the users are free to insert any contractual issues related to the project by selecting the 'new issue' button. Then, the users store the details of the contractual issue into the database system, especially for the description of the issue, and action/solution to resolve the issue.

\subsection{Database}

By selecting the database feature in the main menu, the options of 'project list' and 'issue list' will be displayed. Both options provide an individual interface for users to view the data. The 'project list' stores the project information; whereas the 'issue list' stores the details of the contractual issue.

The data administrator can manage the data and users can make changes to the references. Furthermore, a keyword searching feature has been set up at the top right of both the lists, which is able to help the data administrator and users to locate the data easily. 


\subsection{Testing and evaluation}

The database system, CDS was then presented to the local construction industry for testing and evaluation. A total of thirty professional quantity surveyors were involved. The respondents were required to test and evaluate the system by rating their satisfaction on four closed-ended questions, based on the scores determined by the researcher, i.e. $0=$ extremely dissatisfied, $30 \%=$ dissatisfied, $50 \%=$ neither satisfied nor dissatisfied, $70 \%=$ satisfied, and $100 \%=$ extremely satisfied. In addition, an open-ended question for comments and recommendations was also included. Here, the respondents were free to provide their opinions. The results of testing and evaluation are shown in Table 7.

The scoring of all the variables rated above the satisfaction level. However, the practicality of the database obtained the lowest scores. This variable received some reservations from the respondents, which was the evident from the comments posted by the respondents in the open-ended question. The respondents felt that the period of testing was not sufficient to determine the actual practicality of the database system for providing references. Moreover, only two case studies were stored in the database system, where limited contractual issues could be retrieved for references. Nevertheless, all the variables were achieved more than $70 \%$ of the satisfactory level. Thus, it clearly indicates that the database system has received a positive feedback from the respondents in terms of the usefulness and clarity of information, functionality, practicality, and user familiarity.

Furthermore, few suggestions in improving the performance of CDS were proposed by the respondents. For instance, a password should be set to enhance the security of the database. Only the administration personnel or users with the password should be allowed to enter the system. However, the password setting may not be very useful since the coverage of the users of CDS includes everyone in the organization. Therefore, everyone may request to have the password. The only advantage is that the important and confidential information 
divulged to other external people may be prevented. In addition, the respondents also desire to have an additional feature of report printing in the database system for the ease of reading as well as for further reference in an offline mode. Last but not least, an additional keywords searching was suggested at the main menu instead of located only at the sub-menus of the project and issue lists. The searching should be able to retrieve all the relevant data as stored in the contents of the database. All the suggestions provided by the respondents are very useful to enhance the performance of the system in the future development.

\section{Discussion and limitation}

CDS serves as a database template, which is used to document the experiences of disputes concerning contractual issues in the construction projects. Such experiences describe the dispute process from the period of occurrence till the period of resolution. By referring to the valuable experience of the contractual issues, their causes and suggested solutions/measures for similar situations can be avoided in the future. The database system could also provide more references to the users when additional data have been stored into it. However, it is not possible to set-up a rich and informative database within one or two days, or even weeks. It should be noted that accumulation of large amounts of data requires a relatively long period. As a result, the respondents ranked the lowest scores for the practicality of the database compared to the other variables. This was caused by insufficient information stored in the database for every contractual issue. In other words, there may be a situation with little or no results sorted out in the database when the users search for a specific issue. However, most of the respondents believed that CDS could enhance the knowledge of the users in dealing with the contractual issues. It merely requires more patience and time to accumulate sufficient information. 
Experiences of a person dealing with the contractual disputes are not commonly recorded in the construction industry. Therefore, it poses a big challenge for the company to encourage and motivate the employees to share as well as store the experiences into the database system. More often than not, the employees may claim that there is no time to store the information or provide reasons to hide their unwillingness in doing extra work. Some of the employees also lack motivation, as they do not anticipate the reciprocal benefits from transferring the knowledge. Therefore, certain company policies are should be implemented to cultivate and encourage the employees to share the experiences as well as to learn from the database system.

People commonly question the correctness and validity of the information obtained and do not blindly make use of the information without verification or confirmation by a competent person. If the individual does not trust the knowledge received, he is unlikely to make full use of such information. In the present study, the data administrator is required to perform as the verifier who monitors and validates the information in CDS. The person should be an expert, experienced and knowledgeable in contractual issues, for example, a senior contract manager or director of the company. He or she will check and rectify any incorrect information in the database system regularly. The verification process would make the accumulated information more reliable, thereby improving the confidence of the users in using or referring to such data.

As previously mentioned, the database system was developed using Microsoft Office Access. Certain limitations need to be considered for the selection of the software, even though it provides a lot of advantages, particularly on widespread availability and userfriendliness in database applications. Firstly, the total spaces of the Access database are restricted by two gigabytes, which is the upper limit. Therefore, it is not recommended to store or attach any large pictures or other digital contents inside the database, which would 
occupy a lot of spaces of memory. Nonetheless, it is unlikely for the Access database to reach the storage limitation, since most of the data are several megabytes in size. Besides, CDS supports only one user at a time. If user $\mathrm{A}$ is using the database, users $\mathrm{B}$ and $\mathrm{C}$ need to wait until user $\mathrm{A}$ is done. Apart from the web-application platform as mentioned earlier, it is recommended that a more compressive database management system and programming could be adopted to overcome the above-mentioned limitations by employing large SQL databases [36]. It could also incorporate with other innovative technologies such as ANN, 4D technology and other decision supporting tools $[11,37,38]$.

Overall, the paper has contributed practically and theoretically toward avoidance of project disputes, particularly on the contractual issues. To practical contribution, the database system would benefit most to small-medium type of organizations, especially from developing countries as the development of the database is rather simple and economical. It is a practical tool for storing and retrieving the useful information for decision-making. To theoretical contribution, the developed conceptual model is novel in terms of the database's structure, process flow of database development, use of the administrators and information delivery, which is a combination principle from the data warehouse and the relational database. It renders an implication of information system as to dispute avoidance through capturing and storing previous experiences to forestall or resolve similar situations in the future.

\section{Conclusion}

The research has presented a practical approach in dealing with the project disputes by referring to past experiences through a database system. CDS has been developed by using Microsoft Office Access in a systematic and simplified manner, which can assist organizations to develop, organize, store, and retrieve large amounts of data regarding 
contractual issues. The ability of the proposed system was well proven by the professional quantity surveyors in terms of the usefulness and clarity of information, functionality, practicality, and user familiarity of the database. Future research and development should consider incorporating artificial intelligence supporting tools into other areas of project management for making a better informed decision regarding contractual matters in the project such as budget planning and control, resources management, risk management, etc. Eventually, it can be concluded that the present study has drawn an inference on how the information system via CDS can be incorporated into managing previous experiences for avoidance of project disputes, particularly for the contractual issues.

\section{References}

[1] M.Y. Cheng, H.C. Tsai, Y.H. Chiu, Fuzzy case-based reasoning for coping with construction disputes, Expert Systems with Applications 36 (2009) 4106-4113.

[2] C-Y. Chiu, A.D. Russell, Design of a construction management data visualization environment: A top-down approach, Automation in Construction 20(4) 2011 399-417.

[3] S.O. Cheung, C.H. Suen, A multi-attribute utility model for dispute resolution strategy selection, Construction Management and Economics 20(7) (2002) 557-568.

[4] J.H. Chen, KNN based knowledge-sharing model for severe change order disputes in construction, Automation in Construction 17 (2008) 773-779.

[5] S.O. Cheung, N.S. Thomas, K.C. Lam, W.S. Sin, A fuzzy sets model for construction dispute evaluation, Construction Innovation 1 (2001) 117-127.

[6] D.G. Carmichael, Disputes and International Projects. Netherlands: A.A. Balkema Publishers, 2002.

[7] P. Fenn, D. Lowe, C. Speck, Conflict and dispute in construction, Construction Management and Economics 15 (1997) 513-518.

[8] A.S. Hornby, Oxford Advanced Learner's Dictionary. $8^{\text {th }}$ ed.. Oxford University Press, 2010.

[9] N. Muttil, K.W. Chau, Machine learning paradigms for selecting ecologically significant input variables. Engineering Applications of Artificial Intelligence 20(6) (2007) 735-744. 
[10] B. Bygstad, G. Lanestedt, ICT based service innovation - A challenge for project management. International Journal of Project Management 27(3) (2009) 234-242.

[11] K.W. Chau, M. Anson, J.P. Zhang, 4D dynamic construction management and visualization software: 1. Development. Automation in Construction 14 (2005) 512- 524.

[12] Y.C. Lin, Developing construction assistant experience management system using people-based maps, Automation in Construction 17 (2008) 975-982.

[13] K.C. Shin, K. Molenaar, Prediction of construction disputes in change issues, ASCE Conference Proceedings (2000) 534-542.

[14] M. Adenfelt, Exploring the performance of transnational projects: Shared knowledge, coordination and communication, International Journal of Project Management 28(6) (2010) 529-538.

[15] H.Y. Chong, M.Z. Rosli, A Case Study into the Language Structure of Construction Standard Form in Malaysia, International Journal Project Management 28(6) (2010) 601-608.

[16] S.J. Al-Sabah, S.M. Fereig, D.J. Hoare, A database management system to document and analyse construction claims, Advances in Engineering Software 34 (2003) 477-491.

[17] K.C. Iyer, N.B. Chaphalkar, G.A. Joshi, Understanding time delay disputes in construction contracts, International Journal of Project Management 26(2) (2008) 174-184.

[18] S.W. Moon, J.S. Kim, K.N. Kwon, Effectiveness of OLAP-based cost data management in construction cost estimate, Automation in Construction 16 (2007) 336-344.

[19] K.W. Chau, Y. Cao, M. Anson, J.P. Zhang, Application of data warehouse and decision support system in construction management, Automation in Construction 12 (2002) 213-224.

[20] I. Ahmad, S. Azhar, P. Lukauskis, Development of a decision support system using data warehousing to assist builders/developers in site selection, Automation in Construction 13 (2004) 525-542.

[21] F.M. Arain, S.P. Low, Knowledge-based decision support system for management of variation orders for institutional building projects, Automation in Construction 15 (2006) 272-291.

[22] T, Rujirayanyong, J.J. Shi, A project-oriented data warehouse for construction, Automation in Construction 15 (2006) 800-807.

[23] J.S. Chou, J.T. O'Connor, Internet-based preliminary highway construction cost estimating database, Automation in Construction 17 (2007) 65-74.

[24] A.P. Chassiakos, S.P. Sakellaropoulos, A web-based system for managing construction information. Advances in Engineering Software 39 (2008) 865-876. 
[25] S. El-Omari, O. Moselhi, Integrating automated data acquisition technologies for progress reporting of construction projects, Automation in Construction (2011) Article in Press.

[26] M. Kassab, K. Hipel, T. Hegazy, Conflict resolution in construction disputes using the graph model, Journal of Construction Engineering and Management 132 (2006) 1043-1052.

[27] J.H. Chen, S.C. Hsu, Hybrid ANN-CBR for disputed change orders in construction projects, Automation in Construction 17 (2007) 56-64.

[28] P.J. Pratt, J.J. Adamski, Concept of Database Management. $6^{\text {th }}$ ed., Boston: Cengage Learning, 2007.

[29] P., Rob, C. Coronel, K. Crockett, Database Systems: Design, Implementation \& Management. London: Cengage Learning EMEA, 2008.

[30] D. Morley, C.S. Parker, Understanding Computers: Today and Tomorrow, Comprehensive. $12^{\text {th }}$ ed., Boston: Cengage Learning, 2009.

[31] J.R. Turner, The Handbook of Project Based Management. New York: MrGraw-Hill, 2009.

[32] M. MacDonald, Access 2007: The Missing Manual. Sebastopol: O’Reilly Media, 2006.

[33] A. Simpson, M.L. Young, A. Barrows, A. Wells, Microsoft Office Access 2007 All-in-One Desk Reference for Dummies. Indiana: Willey Publishing, 2006.

[34] P. Ponniah, Data Modelling Fundamental: A Practical guide for IT Professionals. New Jersey: John Willy \& Sons, 2007.

[35] H.Y. Chong, B. Balamuralithara, S.C. Chong, Construction contract administration in Malaysia using DFD: a conceptual model, Industrial Management \& Data Systems 111 (2011) 1449-1464.

[36] H.J. Wang, J.P. Zhang, K.W. Chau, M. Anson, 4D dynamic management for construction planning and resource utilization. Automation in Construction 13 (2004) 575- 589.

[37] J.X. Xie, C.T., Cheng, K.W. Chau, Y.Z., Pei, A hybrid adaptive time-delay neural network model for multi-step-ahead prediction of sunspot activity. International Journal of Environment and Pollution 28 (2006) 364-381.

[38] W. Jia, B. Ling, K.W. Chau, L., Heutte, Palmprint Identification Using Restricted Fusion. Applied Mathematics and Computation 205(2008) 927-934. 


\title{
Incorporation of database approach into contractual issues: Methodology and practical guide for organizations
}

\begin{abstract}
A total avoidance of project disputes is an impossible situation. Yet, the purpose should be to identify the perspectives of minimizing disputes or maximizing avoidance. By referring to past experiences on the causes and the suggested solutions, this research reckons that it can assist in avoiding or resolving similar situations at the onset of the dispute occurrence. Therefore, the objectives of the present study are: (a) to propose and develop a practical database system that can be employed by organizations to manage the past experiences, particularly for contractual issues, and (b) to validate and evaluate the database system from related organizations. The development of the database was systematically articulated. Two actual projects were referred prior to finalizing the database system's structure. Microsoft Office Access tool was selected due to its widespread availability and user-friendliness to construction related organizations. The database system was evaluated by thirty professional quantity surveyors and received positive feedback. It renders an insight toward the effort in avoidance of project disputes through the database approach, which can be easily adopted by the organizations.
\end{abstract}

Keywords: Contractual issues; avoidance; methodology; database; construction 


\section{Introduction}

Projects would become more complex when involving a variety of different participant groups with different goals and needs $[1,2]$. Due to the different perceptions and conflicting goals among the project participants, disagreements are inevitable [3, 4]. Such disagreements could result in project disruption and a detrimental relationship between the contractual parties [5]. Consequently, the projects would be affected by time and cost overrun [4].

There are advantages in avoiding disputes when compared to the notion of assuming that disputes are inevitable, and resolving them after growing [6]. However, a total avoidance of the disputes in a project is a rather impossible situation. Hence, the research direction should be to identify the perspectives of minimizing disputes or maximizing avoidance. There is no method of resolving disputes without identifying the causes. The best method of resolving a dispute includes: (a) to detect the basic causes, and (b) remove these causes in advance [6].

This research focuses on construction projects as its complexity and dispute-prone in nature, particularly for contractual issues. By identifying the possible causes from past experiences, the construction players may seek to avoid or forestall similar situations in the future [7]. The experiences refer to the knowledge and skill that individuals have gained through doing something for a period of time [8]. It can be recorded in different forms and media of information and communication technologies for project management $[9,10]$ such as in the minds of the experts, in operating procedures or documents, databases and intranets $[11,12]$. The value of such experiences is immeasurable. Lessons learned from the past dispute cases could provide the project's stakeholders ideas on how to manage and resolve the current problem or subsequent cases [13]. Subsequently, it would assist in making good decisions and also preventing the problem from escalating toward the worst scenario.

As a result, the present study intends to present a database system that could be employed to share and transfer experiences of past disputes as well as provide useful information for 
dispute prevention or minimization. The database system performs both functions of a relational database and a data warehouse. The contents of the system were added by referring to two actual projects. The system was fully prototyped, however, it requires further development in terms of its contents to serve as the data warehousing through the continuous inputs from the organization.

Eventually, the system operates as a hub for coordination and communication support for knowledge sharing, which is able to improve the project performance [14]. The project performance can be improved through identification of the organization's strengths and weaknesses in handling and administering the contractual matters. Moreover, it also assists in dispute resolution and avoidance, for instance, if the disputants have access to a means that could obtain a better knowledge of possible outcomes resulting from the issue, it may facilitate resolving the issue voluntarily at an early stage [13].

\section{Conflicts and Disputes}

'Conflict' and 'dispute' are two distinct ideas [7]. However, most people probably do not recognize the differences between them. According to Cambridge Advanced Leaner's Dictionary $\left(3^{\text {rd }}\right.$ edition), conflict defines as a serious incompatibility between people with opposing opinions, ideas, principles or interest. On the other hand, dispute is defined as an argument or disagreement, especially an official one between, for example, workers and employers or two countries with a common border. Although in ordinary parlance the word of 'conflict' and 'dispute' are used interchangeably, but in fact, conflict is the precursor to a dispute.

Contractual types of conflicts or disputes are one of the root causes for project disputes, which are related the legal principles and contractual obligations in the contract documents [15]. Hence, this research focuses on contractual issues for the database development. In 
order to make clear the contractual issues involved in different stages, in this study, the contractual activities have been organized and arranged according to three main work stages. They are 'Pre-contract Award Stage', 'Construction or Commencement of Work Stage', and 'Post-Commencement Stage', which are modified from The Royal Institute of British Architects (RIBA) Plan of Works. The Plan of Works is shown in Table 1. Subsequently, the three work stages are:

- Pre-contract Award Stage: it relates to the activities involved covering project inception, feasibility, designing and tendering period.

- Construction or Commencement of Work Stage: it relates to the activities involved from the period of contract date starts and ends in a construction project. It would go until practical completion of the project as referring to RIBA Plans of Work. For the ease of classification, the practical completed work would complete before or same on the completion date according to the contract period.

- Post-Commencement Stage: it relates to the activities involved for the period after the practical completion or post practical completion as referring to RIBA Plans of Work.

\section{Information System: Database Approaches toward Project Disputes}

Traditionally, techniques utilized by the construction professionals to transfer experiences often required face-to-face actions, e.g. formal meetings, interviews, etc [12]. However, by employing a database system, a huge amount of data can be handled, properly managed, and referred to easily and quickly [16]. The database collects the experiences from the minds of different people and acts like a central storage to provide references and guidelines to a user's query in a particular manner [17]. 
Despite the increased development of databases in the construction industry [18], a database that deals with contractual disputes is a relatively new concept in the information system. Several previous studies of database applications were reviewed between 2002 and 2011 as shown in Table 2. In general, it can be concluded that a majority of the database applications are related to information management and cost estimation. In addition, the data warehouse and the relational database are the two main types of database applications that involved in the areas of research. The data warehouse is a read-only analytical database that provides a tool-helping project organization in decision making [19]. It plays an important role in a decision support system. On the other hand, the relational database is a database that recognizes the relationships between the different pieces of information [8]. It stores and manages the required information in the database system. Nonetheless, the proposed database system is not exactly a data warehouse or relational database, but is more toward a combination of them. It is not a read-only analytical database or data storage, but it supports the function to enhance knowledge of users in decision making.

An addition to that, several studies have also suggested approaches for overcoming the problem of disputes in the construction industry as shown in Table 3. Shin and Molenaar [13] presented a framework for dispute prediction by defining the critical dispute characteristics and building causal relationships amongst these characteristics. Cheung and others [5] proposed a method to evaluate the construction dispute by applying the fuzzy set theory to analyze the likelihood of occurrence and impact of a dispute. Kassab and others [26] used the graph model to predict decisions during the negotiation process. It provided valuable insights into the strategic characteristics of a dispute. Chen and Hsu [27] developed a model to resolve a potential severe dispute caused by the change orders developed. The model utilized the artificial neutral networks (ANN) to predict the litigation likelihood and case based reasoning $(\mathrm{CBR})$ to yield warnings and display the litigation information related to past 
cases. Chen [4] also developed a knowledge sharing model for information sharing, which was aimed to avoid a litigious construction change dispute. Last but not least, Cheng and others [1] combined the CBR and fuzzy set theory for coping with the construction disputes. It would assist mediators to make decisions in dispute settlement and provide information to the project participants for defending their rights.

Consequently, it can be observed that each study utilizes a different technique in dealing with construction disputes. However, a majority of the techniques involve the complicate theory, which is not easy to comprehend and lack of practical examples for a real practice. In addition, it can be established that historical data or cases were involved in a majority of the studies. Thus, the usefulness and effectiveness of past knowledge or experiences in dealing with the construction dispute have been recognized. The above overview is useful to clarify the differences between the present study and the other previous approaches in terms of the concept and function of database application as well as the method in dealing with the construction disputes.

\subsection{Database's features and development}

A database is a shared, integrated computer structure that stores information about the types, attributes and relationship of the entities [28]. The term database system refers to an organization of components that refine and regulate the collection, storage, management and use of data within a database environment [29]. In the present study, the database system consists of four major components as illustrated in Fig. 1 such as:

- Hardware refers to the system's physical devices, for example, computer, monitor, etc.

- Software refers to the database management system software. Recently, many types of database tools are available in the market such as Oracle, International Business 
Machines Data Base 2 (IBM DB2), Microsoft Office Access, System Query Language (SQL) Server, Sybase, etc. In the present study, Microsoft Office Access was chosen due to its widespread availability, lower cost [24], and ease of learning. Further, the software is readily available and provides a simple and user-friendly interface.

- People include all the users of the database system. Four types of users have been identified: database system administrator who oversees the database system's operation and ensures the proper functioning, data administrator who manages the data and supports the validity of the information, users who are with the relevant experiences and knowledge in storing the data, and users who are looking for relevant references in extracting the data.

- Data covers the collection of facts stored in the database. In the present study, the word data refers to the experiences of the past contractual dispute in a construction project.

A database can be classified according to the number of users as well as the database location [29]. The numbers of users determine whether the database can support only one user at a time (single-user database) or multiple users at the same time (multi-user database). Meanwhile, the database location determines whether the database can support the data located at a single site (centralized database) or distributed across several different sites (distributed database). In the present study, the proposed database is a centralized database, which is utilized to manage the contractual disputes within a company or an organization. It also serves a single-user database that allows only one user to access at a time. Although, two or more users are able to access the database at the same time, the second and following users can just open the read-only database. This is to prevent the users from making conflicting 
changes to the same data at the same time [30]. However, it can be transformed into a multiuser database or distributed database by applying the web-application platform, for example, Active Server Pages (ASP.NET), Microsoft Share Point, etc. This requires an internet connection as well as better control system and management.

Besides, a good database refers to a database that meets all the user requirements and could improve company's portfolio management, which is a group of projects that share the common resources $[29,31]$. The database system contains database objects such as tables, queries, forms, reports, macros and modules [16]. The functions of the objects include: tables for storing the data, queries for selecting and combining data, forms for viewing or editing the data on-screen, reports for printing the data, macros and modules for programming automation $[32,33]$. The development of the database has been carried out manually. Few contract documents and database examples have been referred to determine the type of information and structure that should be provided by the database.

\subsection{Conceptual Model}

Two case studies were conducted prior to the development of database system to form a template example of data entry. This process would provide chances to verify the functionality of the database's structure in terms of its features, interfaces, and the information that reviewed from literatures. The contract documents were referred to gather the information related to the contractual issues that encountered in the project. Interviews were also carried out with the contract managers who handled the projects. The interviews made clear the data used from the contract documents as well as to check the completeness of the database' structure.

Subsequently, a conceptual model was developed. It is an abstraction of some aspects of the real-world [29]. A model enables a clearer communication about the aspects of the real- 
world and serves as a blueprint to shape and construct the proposed structures [34]. In the present study, the database system aims to manage the contractual issues and provide references to users in the construction industry. Three requirements must be fulfilled for this purpose. Firstly, the database must be simple and easy for the users to insert the data. Secondly, the specific data stored in the database must be found easily and quickly. Lastly, the users must be allowed to manage or edit the existing data.

As a result, the conceptual model describes the requirements of the database system in a process flow as illustrated in Fig. 2. The database is the main component of the system that stores all the relevant data. Data entry provides a means for the users to store the experiences and knowledge into the database. The users must ensure that the particulars of the project have been set up before inserting the details of the issue. The search component provides a tool for the users to extract references from the database. The users may either search on a specific issue for different projects or on all issues for a selected project based on the project characteristics. This conceptual model serves as the main framework for the subsequent development of the database system.

Furthermore, a total of thirty nine contractual issues were identified and derived from literature review through three work stages as shown in Table 4. The users may select the relevant issue from the list during the process of inserting or searching the data. However, it does not mean that the contractual issues are only limited to the above-mentioned thirty nine areas. The users are allowed to add in any new issues into the list after obtaining approval from the data administrator. In addition, the project characteristics utilized to retrieve and sort out a list of the search results are referred to the four elements: construction type (building construction, infrastructure construction, etc.), contract type (fixed firm price contract, lump sum contract, etc.), procurement method (traditional, design \& build, etc.), and standard form of contract (International Federation of Consulting Engineers (FIDIC), Joint Contracts 
Tribunal (JCT), etc.). By selecting any or all of the elements, the historical data with similar characteristics will be sorted out, as requested by the users.

Two types of information are required in the process of setting up a new dispute issue, such as the description of the issue, and the action or solution of dealing with the issue. The description would depict the occurrence of the dispute like the causes, parties involved, and any matters that affect the transformation of the issue. The action or solution describes the manner of dealing with or resolving the dispute event by the parties. It includes the selection of dispute resolution method, process, and outcome.

\section{Contractual Database System}

Contractual Database System (CDS) was developed using Microsoft Office Access based on the model presented in the previous section. The key components include tables, forms, and macros. The database of CDS consists of two tables. The first table captures the project particulars as shown in Table 5. It consists of eighteen fields. This is important as the different project characteristics will have different effects on the contractual issue. The project characteristic will help the users to refine their search. On the other hand, the second table captures the details of the contractual issues. It consists of seven fields as shown in Table 6.

A parent-child or one-to-many relationship has been set between the tables as illustrated in Fig. 3. The table of project particulars is the parent table; whereas the table of contractual issues is the child table. It has been demonstrated that a single project can have any number of contractual issues, but each issue may only refer to a single project. Subsequently, several forms have been created from the tables, while the macros have been set up to automate the custom tasks. The forms are the database objects with attractive interfaces to provide an easy way of viewing or changing the information in a table. Each form of CDS will be discussed 
in detail in the following section. Fig. 4 illustrates the overall framework of the database system.

\subsection{Main menu / 'Home'}

The first interface of CDS describes as the main menu or 'Home'. It is the front page of the system. This is the location where the missions commence and end. Four selections are available in the main menu such as search, data entry, database, and quit. Each selection opens up a sub-menu for further information. For instance, the 'search' option provides a tool for the users to extract data from the system. The 'data entry' option provides a means for users to insert and save the data. The 'database' option is the warehouse for storing the data as well as a place for the users to manage the data. The 'quit' option is used to close the system. The main menu of CDS is illustrated at beginning section of Fig. 4.

\subsection{Search}

The search interface will be displayed after selecting the 'search' button in the main menu. Two options are available in this sub-menu such as project and issue. Both options provide an individual search tool for users to locate the references. The 'project' search tool locates the different contractual issues, which could be retrieved from a particular project. The users may extract the related references from the system based on the project characteristic like construction type, contract type, procurement method, or standard form of contract. The relevant projects will be sorted out in a list after meeting the criteria of the query. From the

list, the users are free to open any projects and review the contractual issues that developed in the project.

Meanwhile, the 'contractual issue' search tool extracts a specific contractual issue, which could have occurred in different projects. It is quite similar with the 'project' search tool. 
However, the search tool extracts the references based on a specific contractual issue that sorted out from the thirty six contractual issues.

\subsection{Data entry}

By selecting the data entry feature, a sub-menu will be displayed. Two options are available such as new project and new issue. If a project has never been recorded in the system, the users are recommended to select the 'New Project' button. After that, the users require to fill up the project particulars such as name, title, location, project characteristics, name of the project team member, contract value, and project duration.

After the project particulars have been recorded in the system, the users are free to insert any contractual issues related to the project by selecting the 'new issue' button. Then, the users store the details of the contractual issue into the database system, especially for the description of the issue, and action/solution to resolve the issue.

\subsection{Database}

By selecting the database feature in the main menu, the options of 'project list' and 'issue list' will be displayed. Both options provide an individual interface for users to view the data. The 'project list' stores the project information; whereas the 'issue list' stores the details of the contractual issue.

The data administrator can manage the data and users can make changes to the references. Furthermore, a keyword searching feature has been set up at the top right of both the lists, which is able to help the data administrator and users to locate the data easily. 


\subsection{Testing and evaluation}

The database system, CDS was then presented to the local construction industry for testing and evaluation. A total of thirty professional quantity surveyors were involved. The respondents were required to test and evaluate the system by rating their satisfaction on four closed-ended questions, based on the scores determined by the researcher, i.e. $0=$ extremely dissatisfied, $30 \%=$ dissatisfied, $50 \%=$ neither satisfied nor dissatisfied, $70 \%=$ satisfied, and $100 \%=$ extremely satisfied. In addition, an open-ended question for comments and recommendations was also included. Here, the respondents were free to provide their opinions. The results of testing and evaluation are shown in Table 7.

The scoring of all the variables rated above the satisfaction level. However, the practicality of the database obtained the lowest scores. This variable received some reservations from the respondents, which was the evident from the comments posted by the respondents in the open-ended question. The respondents felt that the period of testing was not sufficient to determine the actual practicality of the database system for providing references. Moreover, only two case studies were stored in the database system, where limited contractual issues could be retrieved for references. Nevertheless, all the variables were achieved more than $70 \%$ of the satisfactory level. Thus, it clearly indicates that the database system has received a positive feedback from the respondents in terms of the usefulness and clarity of information, functionality, practicality, and user familiarity.

Furthermore, few suggestions in improving the performance of CDS were proposed by the respondents. For instance, a password should be set to enhance the security of the database. Only the administration personnel or users with the password should be allowed to enter the system. However, the password setting may not be very useful since the coverage of the users of CDS includes everyone in the organization. Therefore, everyone may request to have the password. The only advantage is that the important and confidential information 
divulged to other external people may be prevented. In addition, the respondents also desire to have an additional feature of report printing in the database system for the ease of reading as well as for further reference in an offline mode. Last but not least, an additional keywords searching was suggested at the main menu instead of located only at the sub-menus of the project and issue lists. The searching should be able to retrieve all the relevant data as stored in the contents of the database. All the suggestions provided by the respondents are very useful to enhance the performance of the system in the future development.

\section{Discussion and limitation}

CDS serves as a database template, which is used to document the experiences of disputes concerning contractual issues in the construction projects. Such experiences describe the dispute process from the period of occurrence till the period of resolution. By referring to the valuable experience of the contractual issues, their causes and suggested solutions/measures for similar situations can be avoided in the future. The database system could also provide more references to the users when additional data have been stored into it. However, it is not possible to set-up a rich and informative database within one or two days, or even weeks. It should be noted that accumulation of large amounts of data requires a relatively long period. As a result, the respondents ranked the lowest scores for the practicality of the database compared to the other variables. This was caused by insufficient information stored in the database for every contractual issue. In other words, there may be a situation with little or no results sorted out in the database when the users search for a specific issue. However, most of the respondents believed that CDS could enhance the knowledge of the users in dealing with the contractual issues. It merely requires more patience and time to accumulate sufficient information. 
Experiences of a person dealing with the contractual disputes are not commonly recorded in the construction industry. Therefore, it poses a big challenge for the company to encourage and motivate the employees to share as well as store the experiences into the database system. More often than not, the employees may claim that there is no time to store the information or provide reasons to hide their unwillingness in doing extra work. Some of the employees also lack motivation, as they do not anticipate the reciprocal benefits from transferring the knowledge. Therefore, certain company policies are should be implemented to cultivate and encourage the employees to share the experiences as well as to learn from the database system.

People commonly question the correctness and validity of the information obtained and do not blindly make use of the information without verification or confirmation by a competent person. If the individual does not trust the knowledge received, he is unlikely to make full use of such information. In the present study, the data administrator is required to perform as the verifier who monitors and validates the information in CDS. The person should be an expert, experienced and knowledgeable in contractual issues, for example, a senior contract manager or director of the company. He or she will check and rectify any incorrect information in the database system regularly. The verification process would make the accumulated information more reliable, thereby improving the confidence of the users in using or referring to such data.

As previously mentioned, the database system was developed using Microsoft Office Access. Certain limitations need to be considered for the selection of the software, even though it provides a lot of advantages, particularly on widespread availability and userfriendliness in database applications. Firstly, the total spaces of the Access database are restricted by two gigabytes, which is the upper limit. Therefore, it is not recommended to store or attach any large pictures or other digital contents inside the database, which would 
occupy a lot of spaces of memory. Nonetheless, it is unlikely for the Access database to reach the storage limitation, since most of the data are several megabytes in size. Besides, CDS supports only one user at a time. If user $\mathrm{A}$ is using the database, users $\mathrm{B}$ and $\mathrm{C}$ need to wait until user $\mathrm{A}$ is done. Apart from the web-application platform as mentioned earlier, it is recommended that a more compressive database management system and programming could be adopted to overcome the above-mentioned limitations by employing large SQL databases [36]. It could also incorporate with other innovative technologies such as ANN, 4D technology and other decision supporting tools $[11,37,38]$.

Overall, the paper has contributed practically and theoretically toward avoidance of project disputes, particularly on the contractual issues. To practical contribution, the database system would benefit most to small-medium type of organizations, especially from developing countries as the development of the database is rather simple and economical. It is a practical tool for storing and retrieving the useful information for decision-making. To theoretical contribution, the developed conceptual model is novel in terms of the database's structure, process flow of database development, use of the administrators and information delivery, which is a combination principle from the data warehouse and the relational database. It renders an implication of information system as to dispute avoidance through capturing and storing previous experiences to forestall or resolve similar situations in the future.

\section{Conclusion}

The research has presented a practical approach in dealing with the project disputes by referring to past experiences through a database system. CDS has been developed by using Microsoft Office Access in a systematic and simplified manner, which can assist organizations to develop, organize, store, and retrieve large amounts of data regarding 
contractual issues. The ability of the proposed system was well proven by the professional quantity surveyors in terms of the usefulness and clarity of information, functionality, practicality, and user familiarity of the database. Future research and development should consider incorporating artificial intelligence supporting tools into other areas of project management for making a better informed decision regarding contractual matters in the project such as budget planning and control, resources management, risk management, etc. Eventually, it can be concluded that the present study has drawn an inference on how the information system via CDS can be incorporated into managing previous experiences for avoidance of project disputes, particularly for the contractual issues.

\section{References}

[1] M.Y. Cheng, H.C. Tsai, Y.H. Chiu, Fuzzy case-based reasoning for coping with construction disputes, Expert Systems with Applications 36 (2009) 4106-4113.

[2] C-Y. Chiu, A.D. Russell, Design of a construction management data visualization environment: A top-down approach, Automation in Construction 20(4) 2011 399-417.

[3] S.O. Cheung, C.H. Suen, A multi-attribute utility model for dispute resolution strategy selection, Construction Management and Economics 20(7) (2002) 557-568.

[4] J.H. Chen, KNN based knowledge-sharing model for severe change order disputes in construction, Automation in Construction 17 (2008) 773-779.

[5] S.O. Cheung, N.S. Thomas, K.C. Lam, W.S. Sin, A fuzzy sets model for construction dispute evaluation, Construction Innovation 1 (2001) 117-127.

[6] D.G. Carmichael, Disputes and International Projects. Netherlands: A.A. Balkema Publishers, 2002.

[7] P. Fenn, D. Lowe, C. Speck, Conflict and dispute in construction, Construction Management and Economics 15 (1997) 513-518.

[8] A.S. Hornby, Oxford Advanced Learner's Dictionary. $8^{\text {th }}$ ed.. Oxford University Press, 2010.

[9] N. Muttil, K.W. Chau, Machine learning paradigms for selecting ecologically significant input variables. Engineering Applications of Artificial Intelligence 20(6) (2007) 735-744. 
[10] B. Bygstad, G. Lanestedt, ICT based service innovation - A challenge for project management. International Journal of Project Management 27(3) (2009) 234-242.

[11] K.W. Chau, M. Anson, J.P. Zhang, 4D dynamic construction management and visualization software: 1. Development. Automation in Construction 14 (2005) 512- 524.

[12] Y.C. Lin, Developing construction assistant experience management system using people-based maps, Automation in Construction 17 (2008) 975-982.

[13] K.C. Shin, K. Molenaar, Prediction of construction disputes in change issues, ASCE Conference Proceedings (2000) 534-542.

[14] M. Adenfelt, Exploring the performance of transnational projects: Shared knowledge, coordination and communication, International Journal of Project Management 28(6) (2010) 529-538.

[15] H.Y. Chong, M.Z. Rosli, A Case Study into the Language Structure of Construction Standard Form in Malaysia, International Journal Project Management 28(6) (2010) 601-608.

[16] S.J. Al-Sabah, S.M. Fereig, D.J. Hoare, A database management system to document and analyse construction claims, Advances in Engineering Software 34 (2003) 477-491.

[17] K.C. Iyer, N.B. Chaphalkar, G.A. Joshi, Understanding time delay disputes in construction contracts, International Journal of Project Management 26(2) (2008) 174-184.

[18] S.W. Moon, J.S. Kim, K.N. Kwon, Effectiveness of OLAP-based cost data management in construction cost estimate, Automation in Construction 16 (2007) 336-344.

[19] K.W. Chau, Y. Cao, M. Anson, J.P. Zhang, Application of data warehouse and decision support system in construction management, Automation in Construction 12 (2002) 213-224.

[20] I. Ahmad, S. Azhar, P. Lukauskis, Development of a decision support system using data warehousing to assist builders/developers in site selection, Automation in Construction 13 (2004) 525-542.

[21] F.M. Arain, S.P. Low, Knowledge-based decision support system for management of variation orders for institutional building projects, Automation in Construction 15 (2006) 272-291.

[22] T, Rujirayanyong, J.J. Shi, A project-oriented data warehouse for construction, Automation in Construction 15 (2006) 800-807.

[23] J.S. Chou, J.T. O'Connor, Internet-based preliminary highway construction cost estimating database, Automation in Construction 17 (2007) 65-74.

[24] A.P. Chassiakos, S.P. Sakellaropoulos, A web-based system for managing construction information. Advances in Engineering Software 39 (2008) 865-876. 
[25] S. El-Omari, O. Moselhi, Integrating automated data acquisition technologies for progress reporting of construction projects, Automation in Construction (2011) Article in Press.

[26] M. Kassab, K. Hipel, T. Hegazy, Conflict resolution in construction disputes using the graph model, Journal of Construction Engineering and Management 132 (2006) 1043-1052.

[27] J.H. Chen, S.C. Hsu, Hybrid ANN-CBR for disputed change orders in construction projects, Automation in Construction 17 (2007) 56-64.

[28] P.J. Pratt, J.J. Adamski, Concept of Database Management. $6^{\text {th }}$ ed., Boston: Cengage Learning, 2007.

[29] P., Rob, C. Coronel, K. Crockett, Database Systems: Design, Implementation \& Management. London: Cengage Learning EMEA, 2008.

[30] D. Morley, C.S. Parker, Understanding Computers: Today and Tomorrow, Comprehensive. $12^{\text {th }}$ ed., Boston: Cengage Learning, 2009.

[31] J.R. Turner, The Handbook of Project Based Management. New York: MrGraw-Hill, 2009.

[32] M. MacDonald, Access 2007: The Missing Manual. Sebastopol: O’Reilly Media, 2006.

[33] A. Simpson, M.L. Young, A. Barrows, A. Wells, Microsoft Office Access 2007 All-in-One Desk Reference for Dummies. Indiana: Willey Publishing, 2006.

[34] P. Ponniah, Data Modelling Fundamental: A Practical guide for IT Professionals. New Jersey: John Willy \& Sons, 2007.

[35] H.Y. Chong, B. Balamuralithara, S.C. Chong, Construction contract administration in Malaysia using DFD: a conceptual model, Industrial Management \& Data Systems 111 (2011) 1449-1464.

[36] H.J. Wang, J.P. Zhang, K.W. Chau, M. Anson, 4D dynamic management for construction planning and resource utilization. Automation in Construction 13 (2004) 575- 589.

[37] J.X. Xie, C.T., Cheng, K.W. Chau, Y.Z., Pei, A hybrid adaptive time-delay neural network model for multi-step-ahead prediction of sunspot activity. International Journal of Environment and Pollution 28 (2006) 364-381.

[38] W. Jia, B. Ling, K.W. Chau, L., Heutte, Palmprint Identification Using Restricted Fusion. Applied Mathematics and Computation 205(2008) 927-934. 
Table 1: RIBA Plans of Work

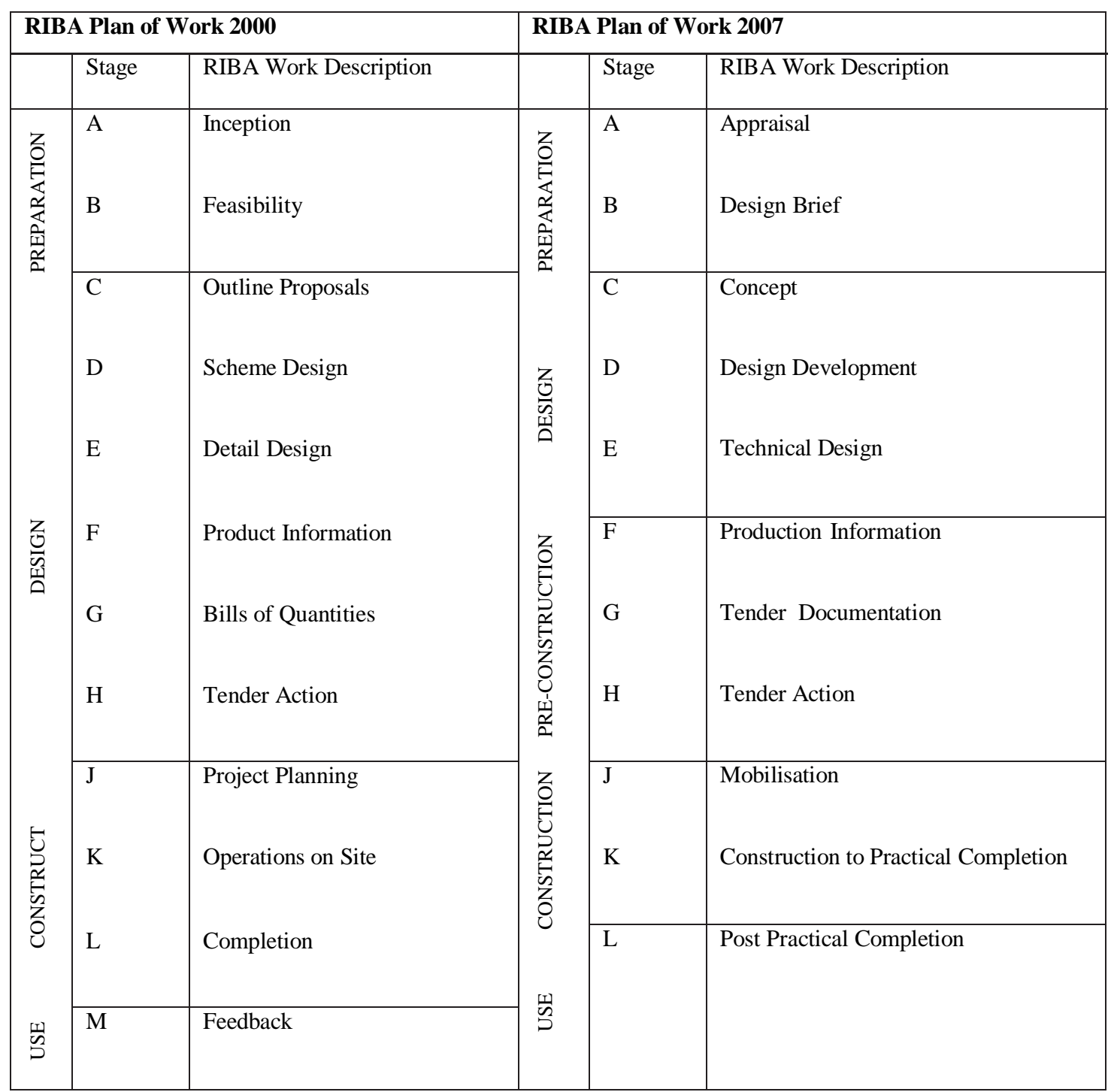

(Source: Royal Institute of British Architects, 2007) 
Table 2: Previous studies of database application

\begin{tabular}{lcll}
\hline System/Name & Year & $\begin{array}{l}\text { Type of } \\
\text { database }\end{array}$ & Functions \\
\hline $\begin{array}{l}\text { Construction Management Decision } \\
\text { Support System (CMDSS) [19] }\end{array}$ & 2002 & $\begin{array}{l}\text { data } \\
\text { warehouse }\end{array}$ & $\begin{array}{l}\text { Construction management, help managers in } \\
\text { making decisions to improve management } \\
\text { performance }\end{array}$ \\
$\begin{array}{l}\text { Claims database management system } \\
\text { [16] }\end{array}$ & 2003 & $\begin{array}{l}\text { relational } \\
\text { database }\end{array}$ & Document and analyse construction claims \\
$\begin{array}{l}\text { Decision Support System (DSS) [20] } \\
\text { data } \\
\text { warehouse }\end{array}$ & Assist builders/developers in site selection \\
$\begin{array}{l}\text { knowledge-based decision support } \\
\text { system (KBDSS) [21] }\end{array}$ & 2006 & $\begin{array}{l}\text { knowledge- } \\
\text { base }\end{array}$ & Management of variation orders \\
$\begin{array}{l}\text { Project-Oriented Data Warehouse } \\
\text { (PDW) [22] }\end{array}$ & 2006 & $\begin{array}{l}\text { data } \\
\text { warehouse }\end{array}$ & $\begin{array}{l}\text { Collect and store construction project information } \\
\text { for future use }\end{array}$ \\
$\begin{array}{l}\text { Cost Data Management System } \\
\text { (CDMS) [18] }\end{array}$ & 2007 & $\begin{array}{l}\text { data } \\
\text { warehouse }\end{array}$ & Construction cost estimate \\
$\begin{array}{l}\text { Web-based Preliminary Item-Level } \\
\text { Cost Estimating System (WBPILCES) }\end{array}$ & 2007 & $\begin{array}{l}\text { relational } \\
\text { database }\end{array}$ & Preliminary infrastructure project cost estimation \\
[23] & & $\begin{array}{l}\text { relational } \\
\text { database }\end{array}$ & Managing construction information \\
$\begin{array}{l}\text { Web-based information management } \\
\text { system [24] }\end{array}$ & 2008 & $\begin{array}{l}\text { relational } \\
\text { database }\end{array}$ & $\begin{array}{l}\text { Assist in performing project tracking and control } \\
\text { functions, and in management of construction } \\
\text { claims }\end{array}$ \\
$\begin{array}{l}\text { Integrating automated data acquisition } \\
\text { technologies [25] }\end{array}$ & 2011 & \\
\hline
\end{tabular}


Table 3: Previous studies of model in resolving project disputes

\begin{tabular}{llllll}
\hline System/Name & Year & $\begin{array}{l}\text { Method of decision } \\
\text { making/process }\end{array}$ & $\begin{array}{l}\text { Use of } \\
\text { historical } \\
\text { data/cases }\end{array}$ & $\begin{array}{l}\text { Targeted dispute } \\
\text { issue }\end{array}$ & $\begin{array}{l}\text { Use of IT } \\
\text { tool }\end{array}$ \\
\hline $\begin{array}{l}\text { Model of construction } \\
\text { disputes prediction }\end{array}$ & 2000 & Case-based reasoning & Yes & $\begin{array}{l}\text { Change-related } \\
\text { disputes }\end{array}$ & $\begin{array}{l}\text { Yes } \\
\text { (conceptual) }\end{array}$ \\
$\begin{array}{l}\text { [13] } \\
\begin{array}{l}\text { Model of fuzzy CDE } \\
\text { system [5] }\end{array}\end{array}$ & 2001 & Fuzzy sets theory & No & $\begin{array}{l}\text { General construction } \\
\text { disputes }\end{array}$ & No \\
$\begin{array}{l}\text { Graph model for } \\
\text { conflict resolution [26] }\end{array}$ & 2006 & Graph model & No & $\begin{array}{l}\text { General construction } \\
\text { conflicts and } \\
\text { disputes }\end{array}$ & Yes \\
$\begin{array}{l}\text { Hybrid ANN-CBR } \\
\text { model (HACM) [27] }\end{array}$ & 2007 & $\begin{array}{l}\text { Artificial neutral } \\
\text { network, case based } \\
\text { reasoning }\end{array}$ & Yes & $\begin{array}{l}\text { Change orders- } \\
\text { related disputes }\end{array}$ & Yes \\
$\begin{array}{l}\text { KNN base knowledge- } \\
\text { sharing model [4] }\end{array}$ & 2008 & $\begin{array}{l}\text { K nearest neighbour } \\
\text { classification }\end{array}$ & Yes & $\begin{array}{l}\text { Construction change } \\
\text { disputes }\end{array}$ & Yes \\
$\begin{array}{l}\text { Model of FCBR } \\
\text { system [1] }\end{array}$ & 2009 & $\begin{array}{l}\text { Fuzzy case-based } \\
\text { reasoning }\end{array}$ & Yes & $\begin{array}{l}\text { General construction } \\
\text { disputes }\end{array}$ & $\begin{array}{l}\text { Yes } \\
\text { (conceptual) }\end{array}$ \\
\hline
\end{tabular}


Table 4: Contractual issues in three work stages [35]

\begin{tabular}{|c|c|c|}
\hline Pre-contract award stage & $\begin{array}{c}\text { Construction or commencement of work } \\
\text { stage }\end{array}$ & Post-commencement stage \\
\hline $\begin{array}{ll}\text { 1. } & \text { Estimating and pricing } \\
\text { 2. } & \text { Design information } \\
\text { 3. } & \text { Insurances } \\
\text { 4. } & \text { Performance bond submission } \\
\text { 5. } & \text { Site possession } \\
\text { 6. } & \text { Tender documentation and } \\
\text { requirements } \\
\text { 7. } & \text { Work program }\end{array}$ & $\begin{array}{ll}\text { 1. } & \text { Accessing to site } \\
\text { 2. } & \text { Compensation/loss and expenses } \\
\text { 3. } & \text { Default on notice } \\
\text { 4. } & \text { Delay and extension of time } \\
\text { 5. Discrepancy and inconsistency of } \\
\text { information } \\
\text { 6. Fluctuation of price } \\
\text { 7. Interference/problem by subcontractors } \\
\text { and suppliers } \\
\text { 8. Interference/problem by professionals } \\
\text { 9. Interim payment } \\
\text { 10. Partial possession } \\
\text { 11. Period of honoring certificates } \\
\text { 12. Postponement or suspension of work } \\
\text { 13. Practical completion } \\
\text { 14. Quality of workmanship } \\
\text { 15. Set off by employer } \\
\text { 16. Site and nature of work } \\
\text { 17. Standard and quality of material } \\
\text { 18. Statutory obligations } \\
\text { 19. Supply difficulties } \\
\text { 20. Testing and inspection } \\
\text { 21. Valuation and measurement (work done) } \\
\text { 22. Contractual variations } \\
\text { 23. Weather }\end{array}$ & $\begin{array}{ll}\text { 1. } & \text { Defect liability period } \\
\text { 2. } & \text { Defects } \\
\text { 3. } & \text { Determination } \\
\text { 4. } & \text { Dispute resolution } \\
\text { 5. } & \text { Final account and } \\
& \text { certificate } \\
\text { 6. } & \text { Liquidated damages } \\
\text { 7. } & \text { Outstanding claim and } \\
\text { set off } \\
\text { 8. }\end{array}$ \\
\hline
\end{tabular}


Table 5: Table of project particulars

\begin{tabular}{|c|c|c|}
\hline Field & Data type & Description \\
\hline \multicolumn{3}{|l|}{ General } \\
\hline 1. Project Name & Text & Short name of project \\
\hline 2. Project Title & Memo & Title of project as stated in contract \\
\hline 3. Location & Text & Address of project \\
\hline \multicolumn{3}{|l|}{ Project characteristic } \\
\hline 1. Construction Type & Text & Type of project construction \\
\hline 2. Contract Type & Text & Type of contract used in the project \\
\hline 3. Procurement Method & Text & Type of procurement method used in the project \\
\hline 4. Standard Form of Contract & Text & Type of contract standard form used in the project \\
\hline \multicolumn{3}{|l|}{ Project team } \\
\hline 1. Employer/Client & Text & Name of client/employer \\
\hline 2. Architect & Text & Name of architect \\
\hline 3. Main Contractor & Text & Name of main contractor \\
\hline 4. C\&S Engineer & Text & Name of civil and structural engineer \\
\hline 5. M\&E Engineer & Text & Name of mechanical and electrical engineer \\
\hline 6. Quantity Surveyor & Text & Name of quantity surveyor \\
\hline \multicolumn{3}{|l|}{ Contract value } \\
\hline 1. Original Contract Value & Currency & Original tendering contract value of project \\
\hline 2. Final Contract Value & Currency & Final contract value after completion \\
\hline \multicolumn{3}{|l|}{ Project duration } \\
\hline 1. Duration (Months) & Text & Project duration in months \\
\hline 2. Starting Date & Date/Time & Starting date of project \\
\hline 3. Completion Date & Date/Time & Completion data of project \\
\hline
\end{tabular}


Table 6: Table of contractual issue

\begin{tabular}{|c|c|c|}
\hline Field & Data Type & Description \\
\hline 1. Project Name & Text & Project name of the specific dispute issue \\
\hline 2. Contractual Issue & Text & Contractual dispute issue of project \\
\hline 3. Description & Memo & Summary of the dispute issue \\
\hline 4. Action/Solution & Memo & Solution or action used to resolve the dispute issue \\
\hline 5. Key In Date & Date/Time & Date of data insert \\
\hline 6. Key In By & Text & Name of person insert data \\
\hline 7. Attachment & Attachment & Attach any related file \\
\hline
\end{tabular}


Table 7: Analysis of CDS evaluation

\begin{tabular}{clcc}
\hline No & \multicolumn{1}{c}{ Testing variables } & Mean (\%) & Interpretation \\
\hline 1 & Usefulness and clarity of information in the database & 78.57 & Satisfying \\
2 & $\begin{array}{l}\text { Functionality of database's structure in terms of its features } \\
\text { and interfaces }\end{array}$ & 81.40 & Satisfying \\
3 & $\begin{array}{l}\text { Practicality of the database to provide references and } \\
\text { alertness to the user }\end{array}$ & 71.27 & Satisfying \\
4 & User familiarity to the database (user friendly) & 78.10 & Satisfying \\
\hline
\end{tabular}


Fig. 1: The database system environment

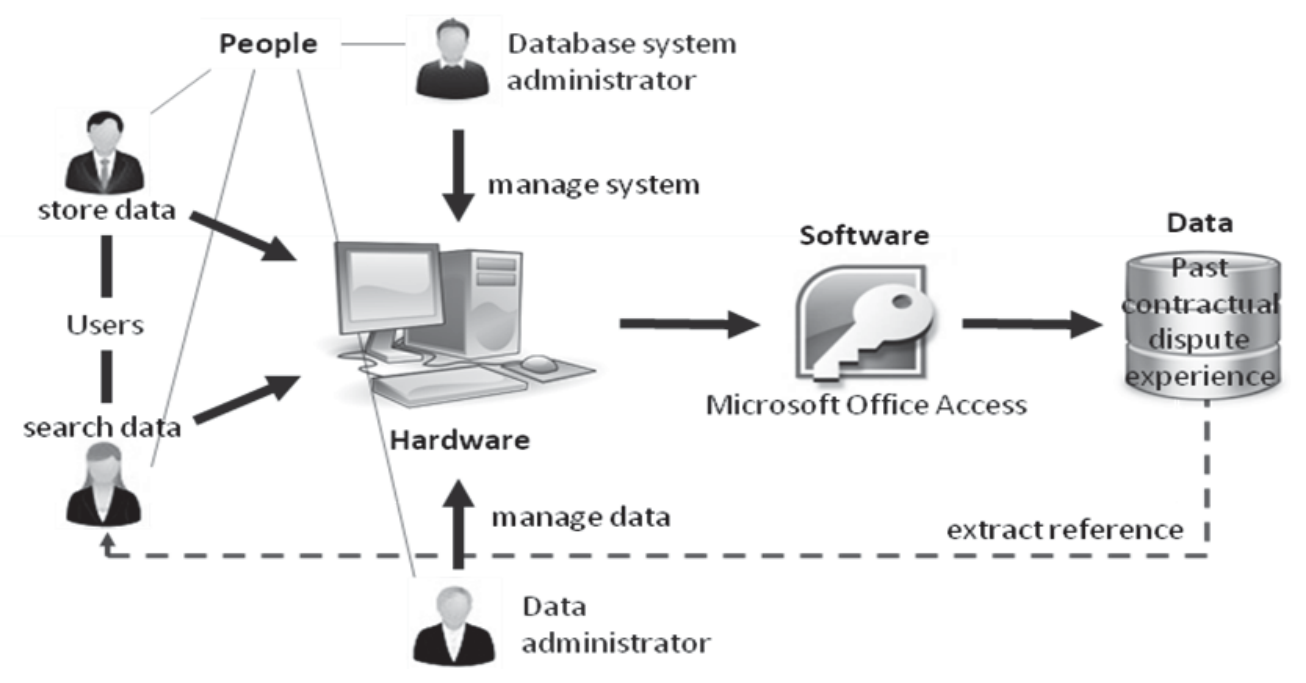


Fig. 2: Model of contractual database system

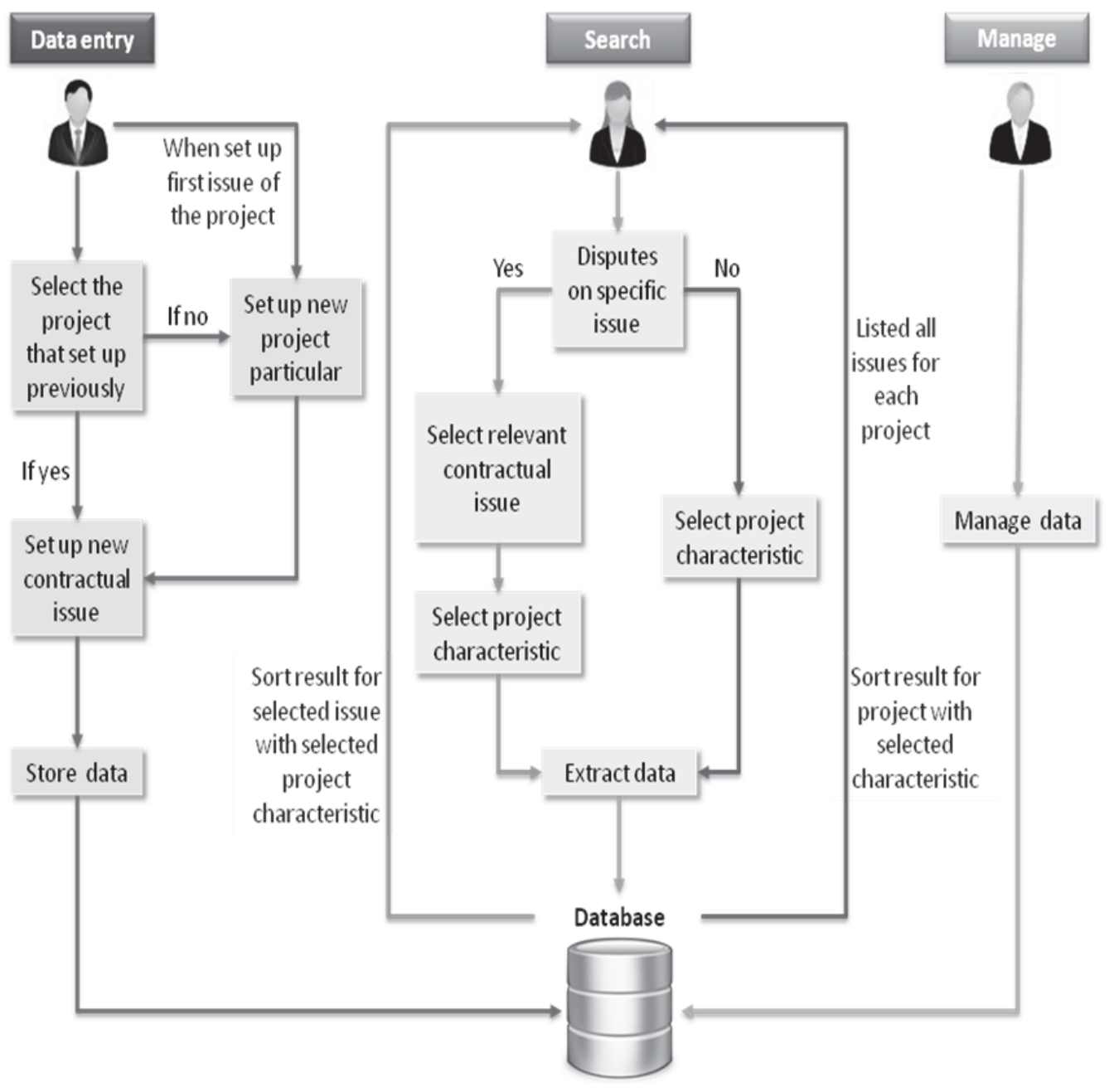


Fig. 3: Relationship between tables in CDS

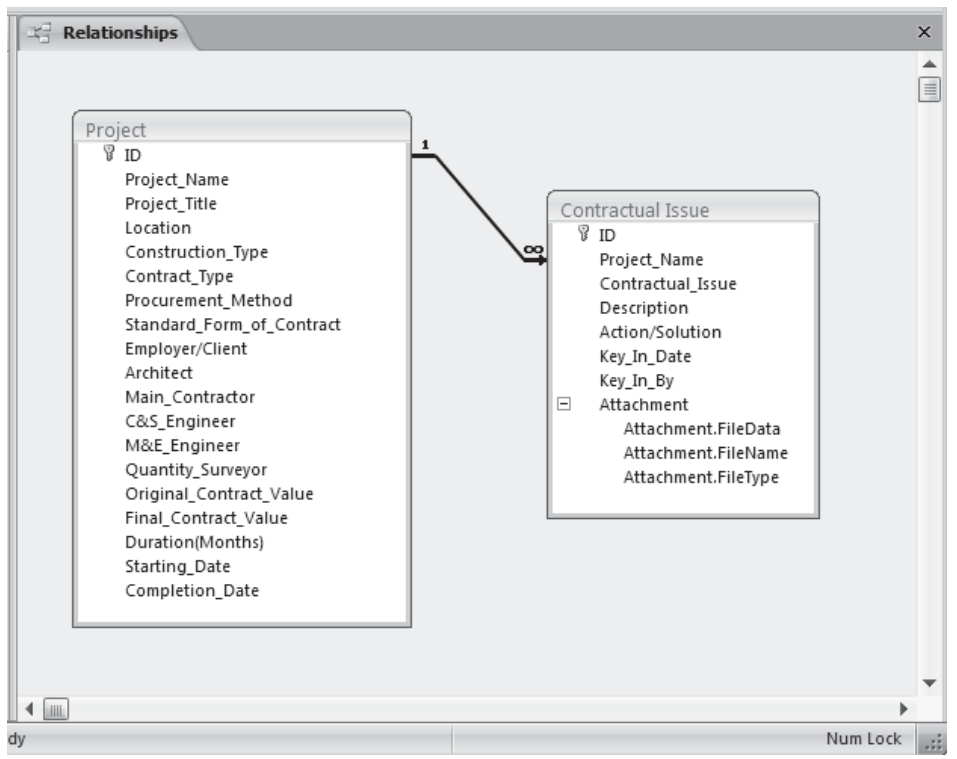


Fig. 4: Overall framework of Contractual Database System

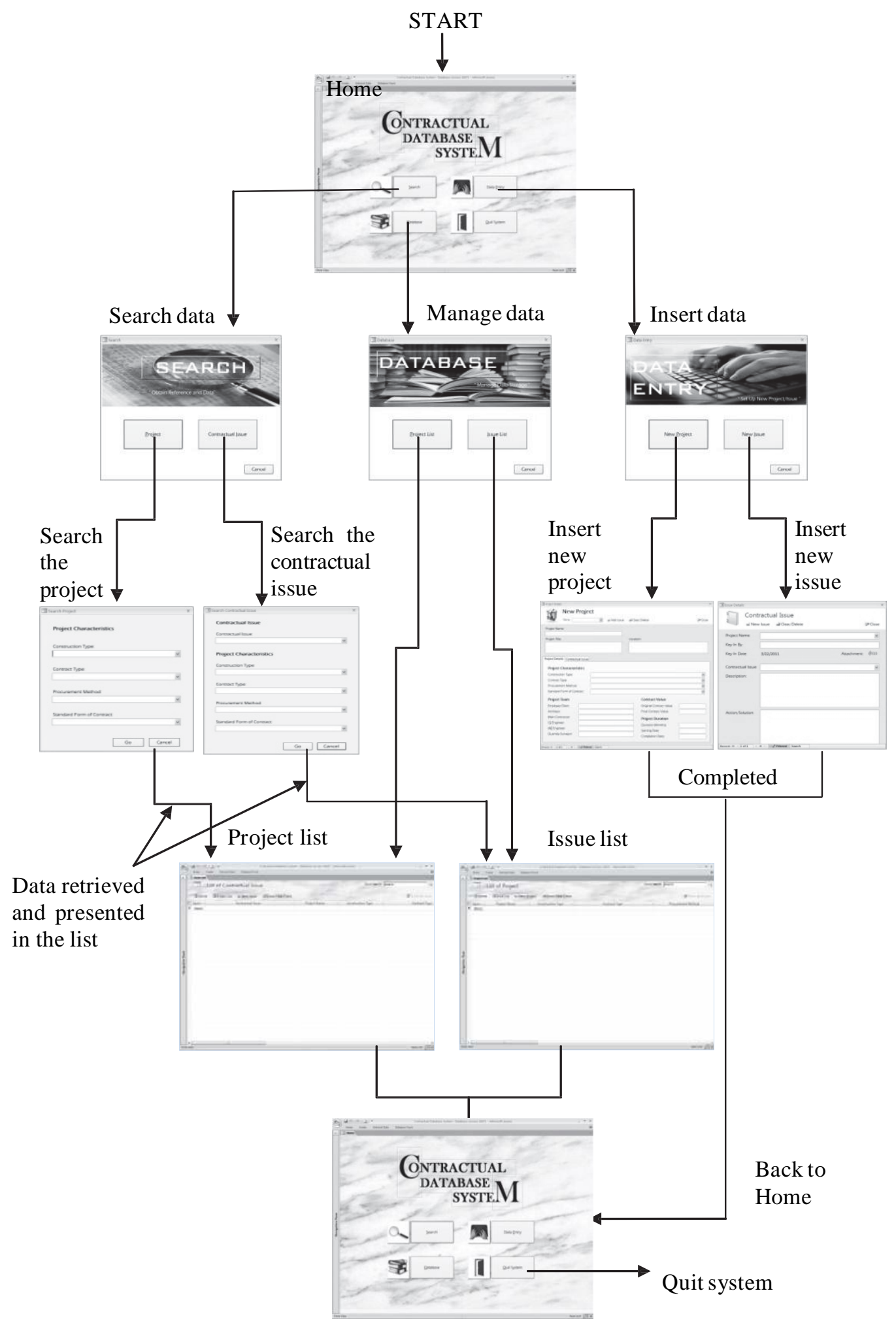

